\title{
Weather warning system in Hungary and the experiences of its operation
}

\author{
Márta SALLAI BURÁNSZKI ${ }^{1,2}$ and Áкos HORVÁTH ${ }^{1}$
}

\begin{abstract}
Extreme environmental events may have catastrophic impacts on the society. Almost $90 \%$ of all natural disasters of the last 10 years have been caused by weather related hazards, i.e. floods, droughts, tropical cyclones and severe storms. The basic task of meteorology is to provide weather forecasts and warnings for public welfare to protect life and property. The weather warning system was set up by the Hungarian Meteorological Service (HMS) in 2006. The first system was capable to provide warnings and alerts for the 7 administrative regions of the country. In 2011 as a result of scientific and methodological development and infrastructural investment, financed by a competition support, the old system was replaced with a sub-regional weather warning system providing weather warnings towards the public, the disaster management and other decision-makers for 174 administrative sub-regions instead of the former seven regions. The first part of this paper provides an overview of the scientific and operational background of the nowcasting system. Then the two years' experiences of its operation will be reviewed. Finally, the problems caused by people's attitude to various weather situations and weather information will be discussed, together with some recommendations to improve the human factor of our professional efforts.
\end{abstract}

Keywords: meteorology, extreme weather, nowcasting, weather services

\section{Introduction}

Because of the swift changes in nature and society, which we have experienced recently, the economic importance of meteorological knowledge has increased. The societies all around the world are more and more sensitive to natural disasters and because of the dangers posed by atmospheric processes, the value of forecasts, nowcasts and their correct interpretation has increased.

\footnotetext{
${ }^{1}$ Hungarian Meteorological Service, H-1024 Budapest, Kitaibel Pál u. 1.

E-mails: sallai.m@met.hu, horvath.a@met.hu

${ }^{2}$ Eszterházy Károly College Doctoral School of Educational Sciences, H-3300 Eger, Eszterházy tér 1.
} 
The advanced industrial and information societies of today are more sensitive to external natural effects, including the effects of meteorological origin. A devastating storm can cause a much bigger damage in high level technology production than $30-50$ years ago. Our society is much more dependent on infrastructure than before. A power outage or a flooded main road can paralyze traffic, commerce, or everyday life for days. It is not incidental that damages caused by natural disasters are significantly larger in the developed countries. At the same time it is important to note that during the period between 1970 and 2008, 95\% of fatalities caused by natural disasters happened in vulnerable developing countries (IPCC, 2011).

The overwhelming majority of natural disasters are of meteorological, climatic, or meteorological origin (e.g. floods) as it is shown by the diagram in the 2010 report of the European Environmental Agency (EEA) providing information on the number of natural disasters between 1998 and 2009, sorted by their types (Figure 1).

The data collected by the Münchener Rückversicherungs-Gesellschaft reinsurance company also shows the unequivocal predominance of weather and climate related catastrophes. In the examined 1980-2012 period, the number of catastrophes increased (Figure 2).

The role meteorology can play in reducing the damage caused by natural disasters is limited. Partly, because it is impossible to prevent extreme weather events, it is only possible to forecast them and partly because $100 \%$ accurate meteorological forecasts do not exist. While an accurate and well-interpreted forecast can save lives, the material value which can be protected is only a smaller part of the estimated value of the damage caused. In Hungary, there were no any research activities concerning on the exact material value, but in some European countries (e.g. Austria, Finland) related economic

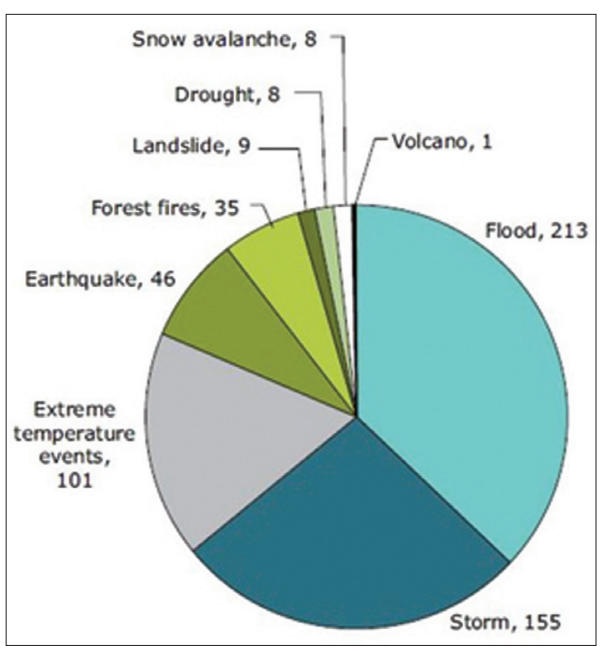
studies are available and the World Meteorological Organization (WMO) also made a statement about it. The studies on investment return of meteorology developments present rates between 1:6 and 1:10, meaning that every invested forint results in savings being 6-10 times larger than the prevented damage.

Fig. 1. Natural disasters in Europe between 1998 and 2009, grouped by the type of the catastrophes. Source: ETC-LUSI/EM-DAT, 2010 


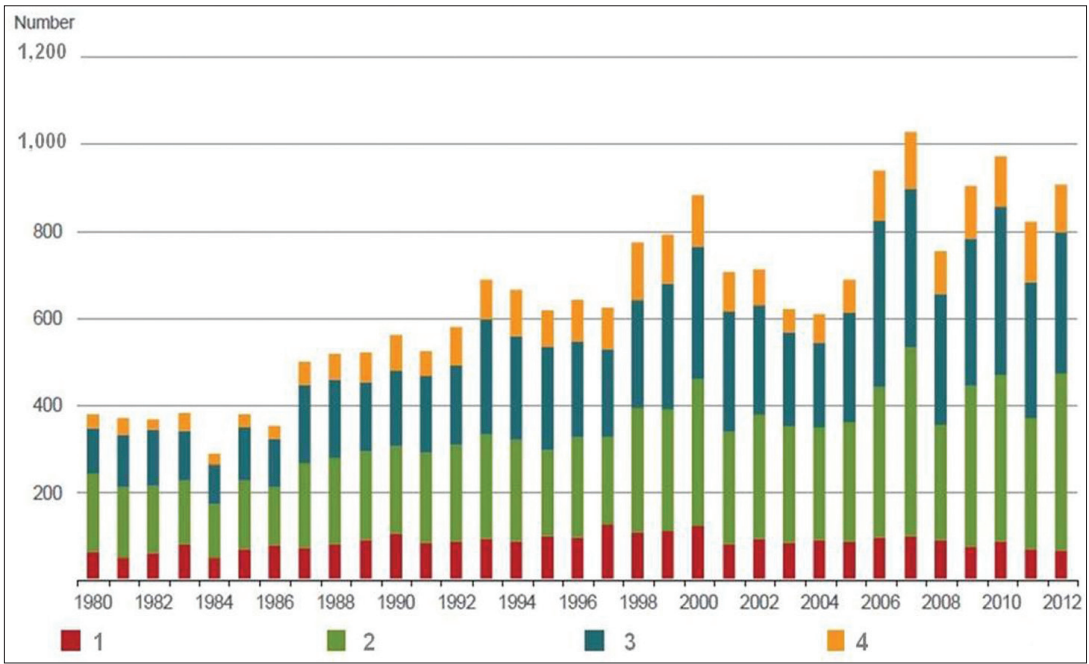

Fig. 2. Natural catastrophes worldwide 1980-2012. Number of events: 1 = geophysical (earthquake, tsunami, volcanic eruption); 2 = meteorological (storm); 3 = hydrological (flood, mass movement); 4 = climatological events (extreme temperature, drought, forest fire). Source: 2013

Münchener Rückversicherungs-Gesellschaft, Geo Risks Research, NatCatSERVICE

\section{The professional basis of weather warnings}

In forecasting atmospheric processes, meteorologists face two main tasks. One of their goals is to be able to create longer-term weather forecasts. The other issue is to tell very accurately whether there is going to be a dangerous weather event at a given point in the next one or two hours and how it will exactly happen. The latest task is the job of nowcasting.

\section{The meteorological background of nowcasting}

The most important requirements of nowcasting are the issues of exact weather forecasts and weather warnings for the next 1-2 hours for an exactly defined place. The ultra short range prediction differs from a regular weather forecast which is usually a prediction for longer periods and for larger areas like counties, regions or states. In that way, weather forecasts can be considered as the part of everyday life, while the importance of nowcasting appears in the case of unusual, severe weather conditions. The applied tools of nowcasting also differ from tools of weather forecasting. In the following section the background of ultra short range forecast and weather warning is presented. 
Most of the severe weather phenomena can be assigned to meteorological objects, such as thunderstorms or cold fronts. To identify them, appropriate meteorological analysis techniques are needed. The techniques apply a wide range of meteorological observations from the surface weather stations to the radar measurements. For example, for a proper description of a convective storm (e.g. a severe thunderstorm), radar measurements are needed to determine the radar reflectivity and the cloud tops of the thunderstorms; to calculate cloud top temperature, satellite information is used; surface observations provide data concerning the inflow of the storm etc. An objective nowcasting system is able to process the above data and recognize severe weather phenomena as objects. The time series of the recognized weather objects allow the computation of displacement and in that way, a forecast by linear extrapolation (Figure 3).

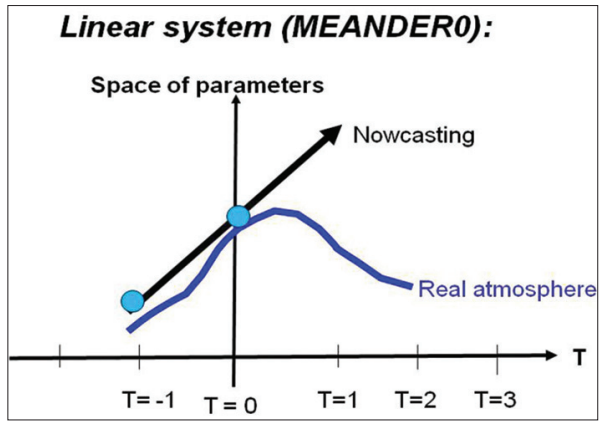

Fig. 3. Schema of linear extrapolation based nowcasting. Basic parameters and analyzed weather objects are linearly extrapolated
The advantage of the object oriented linear nowcasting method is that it is based on observations, so the meteorological objects get in the proper place and at the proper time on the meteorological map. The main disadvantage is the forecast itself: the evolution of severe weather phenomena is significant. The drifting object may become weak or a weaker object can develop to a severe level within a short time. That is why the Lagrangian approach cannot be applied for forecasts longer than 30-40 minutes.

\section{Quasi-linear nowcasting}

Real atmospheric phenomena change in a non-linear way and they often define meteorological objects ambiguously. Instead of the Lagrangian approach, the Navier-Stokes equations based on numerical weather prediction (NWP) models are used for making a dynamical forecast. The highly complex mathematical equations can be solved only by numerical methods requiring large computing capacity. Although NWP models are complex physically based methods to describe the atmosphere, from the point of view of nowcasting, they have limitations. Even the highest resolution and the physically most sophisticated non-hydrostatic models are not able to predict severe weather 
events like thunderstorms exactly. A numerical forecast can be considered as successful if the simulated convection appears close to the place where they are in reality in a few hours. Nevertheless, 6 hours from now, NWP probably produces better forecast than the linear extrapolation because of the non-linear changing feature of the atmosphere.

During the quasi-linear nowcasting procedure a wide range of weather observations is applied to make an objective analysis to describe the present state of the atmosphere. The objective analysis provides the basic parameters (pressure, wind, humidity, etc.) for all grid points of a 3 dimensional grid which covers the domain. At the end of the predicting time interval (for example +3 hours from now), the NWP calculated basic parameters are considered as the most accurate data. Between the analysis and the NWP predicted parameters (between the start and the end point of the forecast period) a linear interpolation is applied for the basic parameters (Figure 4). Using basic parameters the so-called motion vectors can be computed. Motion vectors describe the replacements of weather objects which can be identified in the above described way.

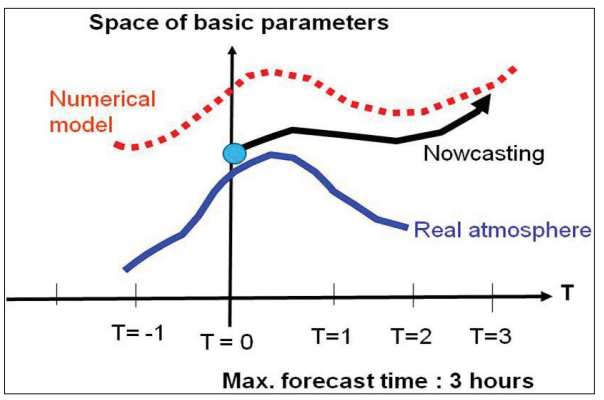

Fig. 4. Schema of quasi-linear nowcasting. At the beginning of the nowcasting period, the analysis is carried out and at the end of the period, an independent numerical forecast is given. The applied method is a linear interpolation.

The advantage of the quasilinear method is that interpolation is applied for meteorological objects instead of extrapolation. Interpolated basic parameters also provide timedependent surrounding conditions to estimate the development of weather objects. The disadvantage is the uncertainty of NWP computing the second pillar of the interpolation.

\section{The coupled nowcasting system}

Due to the development of NWP techniques and the growing computer capacities, the dynamical models play a more important role in nowcasting than before. The main objective is to introduce the real meteorological objects into the models, so that the models can deal with the phenomena complying with the demands of nowcasting. Only high resolution, non-hydrostatic models are suitable for the tasks above because most severe weather events take place at 2-20 km scale (mezo-scale). The models are very sensitive to the initial condition: non-balanced initial fields can produce gravity waves and other numerical instability making the results hardly useable. That is why the assimilation procedure introducing significant weather phenomena into the initial fields has to be very prudent. 
The assimilation of significant weather phenomena consists of 2 steps. The first step is the projection of the measured parameters into the model area. In the case of thunderstorms, radar measurements can provide the most detailed information about the phenomena. Radar data consist of radar reflectivity and tangential wind (Doppler wind). From this information, the so-called radar-operator procedure calculates which parameters are acceptable for the numerical model (pressure, humidity, wind, hydrometeor contents, etc.). The second step is the introduction of the observed and transformed data into the model. It is an efficient method when the model is able to accept the data many times during the integration term. For example, observations are available for $0,1,2$ and 3 hours. The present time is 3 hour and the model starts now, but the simulation time starts at 0 hour. That is way the model can to use $0,1,2$ and 3 hours measures.

When the simulation time is longer than 3 hours, the model runs without any outside forcing. Between 0 and 3 hours, a so-called "nudging term" is applied which forces the model equations to approach the measured data in a way that the effect of the physical consistency doesn't cease. The magnitude of the nudging can be set arbitrarily but it must be kept at a moderate level to avoid instability. The conclusion is that nudging technique may help the model to place the severe weather events to forecast for the appropriate place in appropriate time.

During the coupled nowcasting technique, the above mentioned assimilation procedure is applied for the numerical model and the model runs every hour.

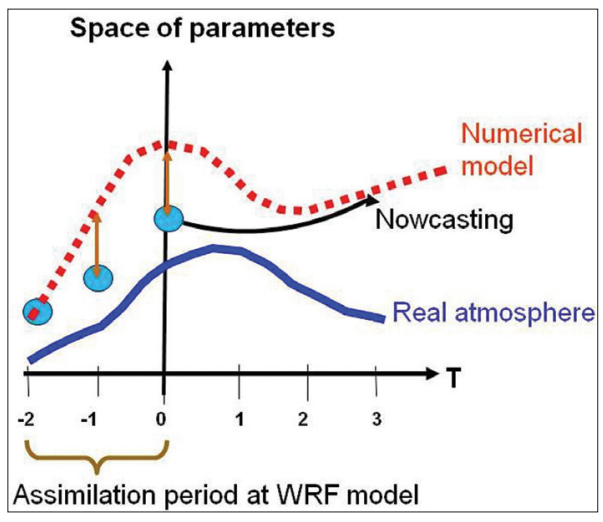

Fig. 5. Schema of coupled nowcasting. Circles represent objective analysis, the nowcasting (black line) blends to numerical forecast. The model has an assimilation period during which significant weather objects are taken into account Nowcasting analyses are produced more frequently (every 10 or 15 minute) and the linear coupling between the analysis and the model forecast is made in the same way as in the case of quasilinear nowcasting (Figure 5).

\section{MEANDER: the nowcasting system of the Hungarian Meteorological Service}

The MEANDER (MEsoscale Analysis, Nowcasting and DEcision Routines) nowcasting system is based both on NWP and real time observation. The MEANDER system makes ultra short range forecast and weather warnings in three steps. 
The first step is the downscaling of the larger-scale weather phenomena to mezo-scale. Larger-scale data come from the ECMWF (European Centre for Medium-Range Weather Forecasts) forecast. ECMWF forecast data are available every 6 hour and they are used for WRF (Weather Research and Forecasting), a limited-area model for initial and lateral conditions. The ECMWF data as boundary conditions for the WRF limited-area model were chosen because of their higher space and time resolutions. The verifications available at the Hungarian Meteorological Service (HMS) also show that the ECMWF model provides better scores for the European domain than any other available largescale model. The WRF model has several options to set and it uses the nonhydrostatic option with sophisticated cloud physic, boundary layer, radiation and other schemes.

Several experiments and case studies were performed to set up the ensemble of the physical parametrization concerning the planetary boundary layer, radiation, cloud physic and soil model parts of the model. The WRF model uses high resolution soil data of Hungary coming from Hungarian academic soil surveys. The land-use input data originate from the Hungarian CORINE database. That model segment is called WRF-ALPHA and the $2.5 \mathrm{~km}$ horizontal resolution allows the cumulus scheme to turn off, i. e. the model is able to compute convective phenomena by basic equations and there is no need for additional parametrization. Regarding the importance of the convection in severe weather events it is an important advantage. WRF-ALPHA runs every $6^{\text {th }}$ hours providing +36 hours numerical forecast allowing to use this product for early warning.

The second step also belongs to the WRF model: $1 \mathrm{~km}$ horizontal resolution is applied for more frequent (every second hour) model runs. The WRFBETA creates +8 hours forecast with 2 hours nudging time. During the very fine model run, the assimilation techniques mentioned at the coupled system are applied. The wind, temperature and humidity observations of automatic weather stations, radar reflectivity and satellite data are involved into the objective analyses which are made every hour. The WRF-BETA model uses the analyses for 2 hours nudging period, that way involving the local scale phenomena into the computations.

The third step of nowcasting is made by the linear segment. That part of the system makes an objective analysis every $10^{\text {th }}$ minutes using data of automatic weather stations and radar and satellite observations. First guess data for the objective analysis come from the actual WRF-BETA model run. The grid of WRF-BETA also defines the domain of the nowcasting system which roughly covers the Carpathian Basin (Figure 6).

The resulting objective analysis contains the basic parameters (pressure, temperature, humidity, wind, etc.) calculated for all grid points. There are several derived parameters, such as visibility, precipitation intensity, the phase of precipitation, etc. A particular method is used for calculating the phase of 


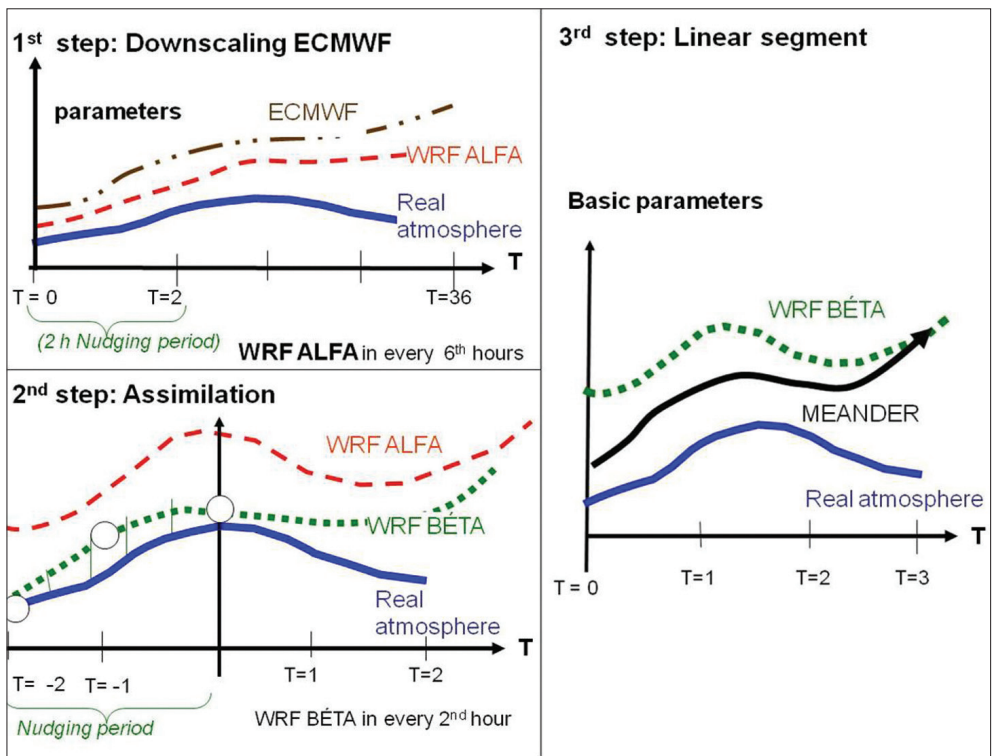

Fig. 6. Scheme of three steps of the MEANDER nowcasting system

precipitation (Geresdi, I. and Horváth, A. 2000). The cloud physic based procedure uses the air column for all grid points and from the vertical profiles of the basic parameters it estimates the phase of the precipitation falling on the surface. The procedure is able to distinguish freezing and frozen rain, snow, graupel and rain. The visibility calculation is based on a simple atmospheric scattering method where the content of hydrometeors is estimated from the mixing value of cloud elements coming from WRF calculations (BENCZE, P. et al. 1982).

Based on the grid data of the objective analysis, the weather objects can be defined: showers, thunderstorms, hailstorms, etc. The final results are "current weather", parameters which identify the actual weather of all grid points. The next step is the linear interpolation of basic parameters between the analysis time and the forecast time 3 hours later coming from the actual WRF-BETA forecast. The basic parameters are three-dimensional data and they allow to calculate atmospheric motion vectors describing the movement of weather objects. The nowcasting of the MEANDER system is based on the movement of weather objects driven by the motion vectors. The moving objects are not necessarily static. Using the WRF-BETA forecast, it is possible to estimate the dynamically predicted weather objects. Comparing them with the analysis, some estimation can be made concerning their development. That phase of MEANDER is still under development. 


\section{Human contribution before final issue of warnings}

The results of the objective procedures above are weather warnings for subregions. The offered warning patterns can be modified by the forecasters using a graphical editor. By rthe help of the editor, arbitrary domains can be assigned and warnings can be issued or cancelled. The forecasters are able to display all the meteorological parameters and fields by the HAWK workstation. The gained information combined with the subjective experience may upgrade the weather warnings.

Manual controls and in case of necessity, manual corrections are made before the final warnings which are sent to the Internet and to the users. On the home page of the Hungarian Meteorological Services everybody can be informed about weather hazards. Some authorities also get weather warnings via direct channels, such as the Civil Protection and Disaster Management Services (Photo 1).

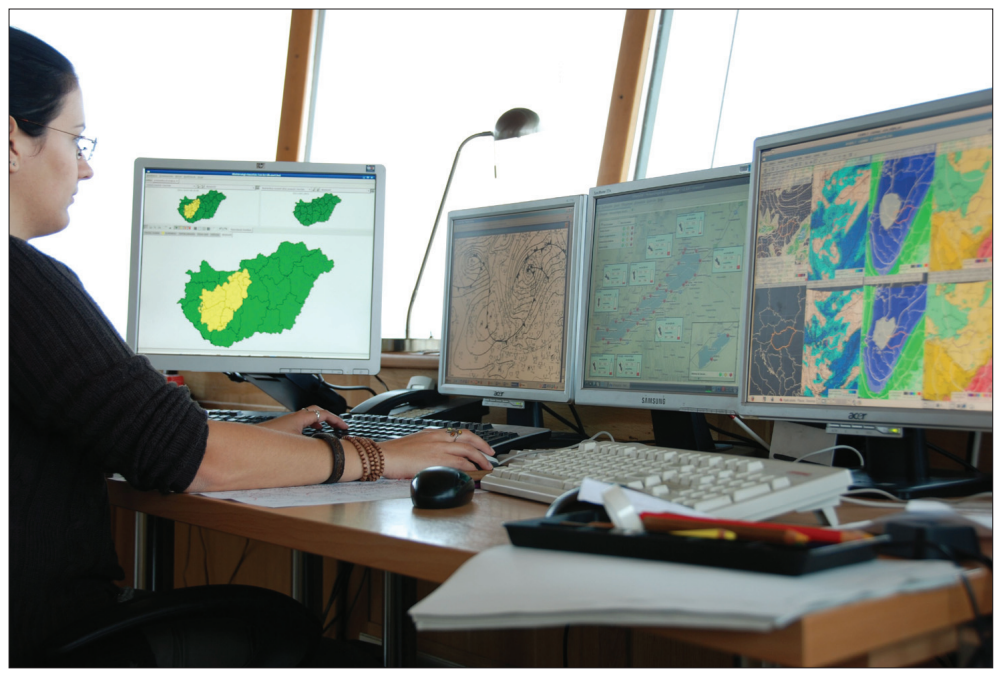

Photo 1. A graphical system is applied to enable the forecasters to modify the automatically produced warnings. The forecasters can use other weather data and they also apply their own experiences

\section{The warning system of the Hungarian Meteorological Service}

The warning system of the HMS realizes the forecast in two steps. During the first step a warning containing the description of the most probable dangerous weather events for the given and the following day is created in the form of a text and a map. 
During the second step, a meteorologist ascertains whether if the given dangerous weather event indicated in the warning is possible under the given weather conditions. Then, $0.5-3$ hours before the event (depending on the weather conditions and the type of the event) an alarm for the dangerous weather event is issued in form of a map.

Warnings and alarms are issued in the case of the following events: intense thunderstorms, heavy rains, wind gusts, sleets and snowdrifts. Some warnings for dangerous weather conditions are issued without any alarms by the system, such as the warnings for long-lasting, high-volume rainfall and snowfall events and the special warnings about the possibility of heat, extreme cold, long-lasting dense fog and ground frost.

During the alarms and warnings, the system distinguishes among three danger levels. If there is no chance of a dangerous event fitting the predefined criteria, the area shows up on the map as green.

- First level (yellow). The weather events in that category are not unusual, but they are potentially dangerous, therefore caution is advised, especially during activities more susceptible to weather.

- Second level (orange). Weather events which carry danger and can lead to damages or even injuries and accidents. It is advised to obtain detailed information regarding the weather.

- Third level (red). Dangerous weather events which can lead to serious damages and threaten human lives. They usually affect extensive areas.

The public can get information on weather emergencies on the Hungarian Meteorological Service website - http://www.met.hu/idojaras/ veszelyjelzes/riasztas/.

\section{Operational experiences}

The sub-regional weather warning system has been in operation since $11 \mathrm{Au}-$ gust 2011. On 16 July 2013, the Hungarian Meteorological Service replaced the sub-regional boundaries to district boundaries in its database connected to nowcasting, so alarms will be issued by districts in the future.

However, it does not mean that there is a substantial change in spatial resolution.

\section{Alarm statistics}

Full-year alarm statistics from 2012 were available only at the end of 2013 when this study was accomplished. There were warnings on 135 days out of 365 days (Figure 7 ). 


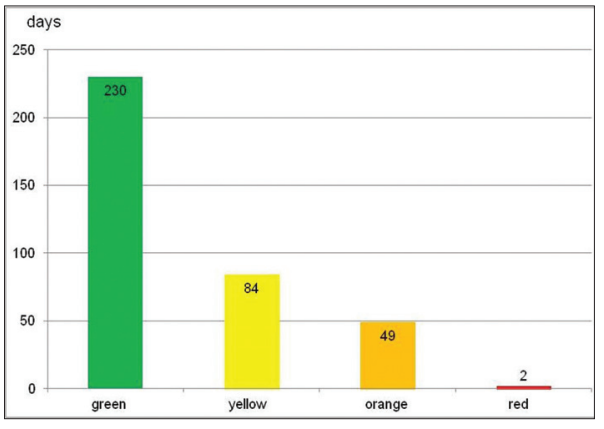

Fig. 7. The number of days for each danger level in 2012 (according to the highest danger level on any given day)
From the point of view of nowcasting, the busiest season is the so-called convective season during the summer. Nearly half $(48 \%)$ of all the orange (level 2) alarms can be linked to intense thunderstorms (with ice pieces reaching $2 \mathrm{~cm}$ and wind gusts over $90 \mathrm{~km} / \mathrm{h}$ ) in the country. The alarms which can be linked to weather events usually happening during the winter season are only about one-fifths $(17 \%)$ of all the alarms. In 2012, there were two red level alarms: one of them was on 19

July because of the strengthening of a thunderstorm system preceding a cold front, the other one happened on 8 December, at the beginning of the meteorological winter when a Mediterranean cyclone caused a snowdrift in the southern regions of the country.

\section{Communication}

Be prepared! But how? The communication of weather forecasts and warnings and the education are very important to make the public aware and prepared. A weather forecast can never be $100 \%$ accurate. In case of nowcasting, on a local scale, the behaviour of the atmosphere is chaotic. So it is necessary to communicate forecast uncertainty to help people make more effective decisions. Presenting potentially hazardous conditions in terms of probabilities, it is very important to make uncertainties understandable to the general public. It is not an easy process.

In the countries where meteorological information and the services of catastrophe management are available, subjective factors define the success of meteorological forecasts and warnings. They are the following: cal dangers.

- Knowledge of the general public about the weather and meteorologi-

- People's attitude to weather situations and weather information.

- Media.

For the better understanding of forecasts, specific knowledge regarding meteorological concepts, forecasts and the question of predictability are necessary. While most of the knowledge could be gathered from various meteorological books and from the Internet, the most effective way would be the spreading of knowledge within the framework of the education system. 
The descriptions in public textbooks dealing with the atmosphere, weather and climate are usually correct and professional, but some basic meteorological knowledge regarding forecasting weather and the benefits and limits of forecasts are missing. They do not deal with dangerous weather phenomena and practical behaviour patterns during weather emergencies, either. To make a progress in this respect, revision and supplementing of learning materials used in public education are needed.

In today's developed societies, especially in the countries where people don't have to face the destructive effects of weather every day, the vulnerability of people to the whims of the weather has decreased. At the same time, most people's behaviour regarding the management of weather events is characterised by becoming too comfortable and moving away from nature. Despite the fact that the communication channels are constantly spouting weather reports, most people don't look up for information about weather events or only do so superficially, even before outdoor activities, work, trips or public holidays.

Many meteorological service providers and the media disseminate a huge range of meteorological information. In many cases, meteorological websites contain information without any official background or quality control misleading the users and in the case of weather warnings, false information can cause catastrophes. People generally do not know which web pages contain accurate information. It is possible to improve the situation with the extension of objective knowledge and public pedagogy.

It is a significant progress that Hungarian broadcasters have been reporting on warnings and alarms issued by the HMS since 2011 when the regulation of catastrophe management and the related tasks of the media were introduced.

\section{Conclusions}

The science of weather forecasting has undergone huge advancements and as a result, meteorology can localize dangerous weather events more and more accurately. The correct usage and interpretation of information in forecasts and nowcasts can protect lives and it can increase the security of people and their valuables or simply contribute to the efficiency of our everyday work or to the spending of our free time.

Since its launch in 2006, the alarm system has become part of the weather related decisions made by the decision-makers and the general public. From an application aspect, replacing the original 7-region resolution to sub-regional and then to district-based alarms was a big step ahead. 
With the methodological and IT developments, we decreased oversecuring and we made a progress in increasing the accuracy of alarms. An important development is the continuous improvement of the MEANDER system providing the basis of nowcasting and the improvement of the communication of dangerous alarms.

\section{REFERENCES}

Bencze, P., Major, Gy. and Mészáros, E. 1982. Fizikai meteorológia (Atmospheric physics). Budapest, Akadémiai Kiadó, 100 p.

BuRÁNSZKI-SALLAI, M. 2010. Everyday adaptation to weather: better to know than to sorrow. In Responsibility, Challenge and Support in Teachers' Life-long Professional Development. Eds. Mészáros, Gy., Falus, I. and Kimmel, M. Budapest, Proceedings of the $35^{\text {th }}$ Annual Conference of ATEE, 23-35.

BurÁNSZKi-SALlAI, M. 2013a. Az időjárás hatása a társadalomra (The impact of weather on society). Természet Világa 3. 118-121.

BuránszKi-SAllai, M. 2013b. A meteorológia szerepe az időjárási károk mérséklésében (The role of meteorology in reduction of damages caused by weather). Természet Világa 4. 156-160.

BuráNSZKI-SALlai, M. 2013c. Az ember és az időjárás viszonya (Relationship between man and weather). Természet Világa 7. 300-304.

BuRÁNSZKI-SALLAI, M. and ÜTô-VISI, J. 2013. Korszerű időjárási ismeretek és racionális viselkedés-minták a földrajzoktatásban (Modern meteorological knowledge and rational behaviour samples in the geography education). In Változó föld, változó társadalom, változó ismeretszerzés 2013. Eds. РАJтóк-TARI, I. and Tóтн, A. Eger, International Scientific Conference, Proceedings, 190-196.

Deutscher Wetterdienst, 2006. Executive summary on the survey "The DWD and Severe Weather Warnings" Deutscher Wetterdienst, 2006. http://www.wmo.int/pages/prog/amp/ pwsp/surveys.htm

Geresdi, I. and Horváth, Á. 2000. Nowcasting of precipitation type. Időjárás 104. (4): 241-252.

Horváth, Á., Geresdi, I. Németh, P. and Dombai, F. 2007. The constitution Day storm in Budapest: Case study of the August 20, 2006 severe storm. Időjárás 111. (1): 41-63.

Horváth, Á., Seres, A. and Németh, P. 2012. Convective systems and periods with large precipitation in Hungary. Időjárás 116. (2): 77-91.

IPCC, 2012. Managing the Risks of Extreme Events and Disasters to Advance Climate Change Adaptation. A Special Report of Working Groups I and II of the Intergovernmental Panel on Climate Change. Eds. Field, C.B., Barros, V., Stocker, T.F., Qin, D., Dokken, D.J., Ebi, K.L., Mastrandrea, M.D., Mach, K.J., Plattner, G.-K., Alllen, S.K., Tignor, M. and Midgley, P.M., Cambridge, UK and New York, USA, Cambridge University Press, $582 \mathrm{p}$.

Münchener Rückversicherungs-Gesellschaft, 2013. Sustainable business and sustainable enviroment. Global warming. Disaster statistics. Münchener Rück, Geo Risks Research, NatCatSERVICE, 2013. http://www.dandc.eu/en/article/munich-res-disaster-statistics-show-climate-change-making-storms-floods-and-draughts-ever 
Ramos, M.H., Mathevet, T., Thielen, J. and Pappenberger, F. 2010. Communicating uncertainty in hydro-meteorological forecasts: mission impossible? Meteorological Applications 17. 223-235.

Strelec Mahovic, N., Horváth, Á. and Csirmaz, K. 2007. Numerical simulation of severe convective phenomena over Croatian and Hungarian territory. Atmospheric Research 83. 121-131.

WMO 2006. Guidelines on Public Weather Services Strategy for Developing Public Education and Outreach. WMO/TD-No. 1354. www.library.wmo.int/pmb_ged/wmo-td_1354.pdf

WMO 2011. Weather extremes in a Changing Climate: Hindsight on Foresight. WMO No. 1075. www.library.wmo.int/pmb_ged/wmo_1075_en.pdf 


\section{GUIDELINES FOR AUTHORS}

Hungarian Geographical Bulletin (formerly Földrajzi Értesítő) is a doubleblind peer-reviewed English-language quarterly journal publishing open access original scientific works in the field of physical and human geography, methodology and analyses in geography, GIS, environmental assessment, regional studies, geographical research in Hungary and Central Europe. In the regular and special issues also discussion papers, chronicles and book reviews can be published.

\section{Manuscript requirements}

We accept most word processing formats, but MSWord files are preferred. Submissions should be single spaced and use 12pt font, and any track changes must be removed. The paper completed with abstract, keywords, text, figures, tables and references should not exceed 6000 words.

The Cover Page of the article should only include the following information: title; author names; a footnote with the affiliations, postal and e-mail addresses of the authors in the correct order; a list of 4 to 8 keywords; any acknowledgements.

An abstract of up to 300 words must be included in the submitted manuscript. It should state briefly and clearly the purpose and setting of the research, methodological backgrounds, the principal findings and major conclusions.

\section{Figures and tables}

Submit each illustration as a separate file. Figures and tables should be referred in the text. Numbering of figures and tables should be consecutively in accordance with their appearance in the text. Lettering and sizing of original artwork should be uniform. Convert the images to TIF or JPEG with an appropriate resolution: for colour or grayscale photographs or vector drawings (min. $300 \mathrm{dpi}$ ); bitmapped line drawings (min.1000 dpi); combinations bitmapped line/photographs (min. $500 \mathrm{dpi}$ ). Please do not supply files that are optimized for screen use (e.g., GIF, BMP, PICT, WPG). Size the illustrations close to the desired dimensions of the printed version. Be sparing in the use of tables and ensure that the data presented in tables do not duplicate results described elsewhere in the article. 


\section{References}

Please ensure that every reference cited in the text is also present in the reference list (and vice versa).

\section{REFERENCE STYLE}

Text: In the text refer to the author's name (small capitals with initials) and year of publication. References should be arranged first chronologically and then further sorted alphabetically if necessary. More than one reference from the same author(s) in the same year must be identified by the letters 'a', 'b', placed after the year of publication.

Example:

(Ridgewell, A.J. 2002; Maher, B.A. et al. 2010) or Ridgewell, A.J. (2002); MAher, B.A. et al. (2010)

Journal papers:

AagaArd, T., Orford, J. and Murray, A.S. 2007. Environmental controls on coastal dune formation; Skallingen Spit, Denmark. Geomorphology 83. (1): 29-47.

Books:

PyE, K. 1987. Aeolian Dust and Dust Deposits. Academic Press, London, 334 p.

Book chapters:

Kovács, J. and VARGA, Gy. 2013. Loess. In: BobrowsKy, P. (Ed.) Encyclopedia of Natural Hazards. Springer, Frankfurt, 637-638.

\section{Submission}

Submission to this journal occurs online. Please submit your article via geobull@mtafki.hu.

All correspondence, including notification of the Editor's decision and requests for revision, takes place by e-mail. 